Urol. int. 1973;28:1

\title{
Contents, Vol. 28, No. 1, 1973
}

Professor Dr. Ferdinand May zum Anlass seines 75. Geburtstages gewidmet Matouschek, E. (Karlsruhe): Professor Dr. Ferdinand May - 75 Jahre alt. ... 5 Knappwost, A. und Matouschek, E. (Karlsruhe): Experimentelle Untersuchungen zur Löslichkeitsbeeinflussung mineralischer Harnkonkremente 9

Strauss, Ingrid (Kreuth): Die Immunologie der Nierentuberkulose und ihre klinische Bedeutung 21

Bergmann, M. und Gollmann, G. (Linz): Ein Beitrag zur retroperitonealen Fibrose 32 Vargas-Delaunoy, F.; Silva-Inzunza, E.; Merhe, E.; Villegas, A., and Dvoredsky, A. (Santiago): Bilateral Ureterocystoplasty with Solely Bladder Tube Flap. An Experimental Study in Dogs 43

Arnholdt, F. (Stuttgart): Radikale transurethrale Elektroresektion des Prostatakarzinoms 50

Ravasini, G. and Pagano, F. (Padua): Surgical Correction of Vesicoureteral Reflux.

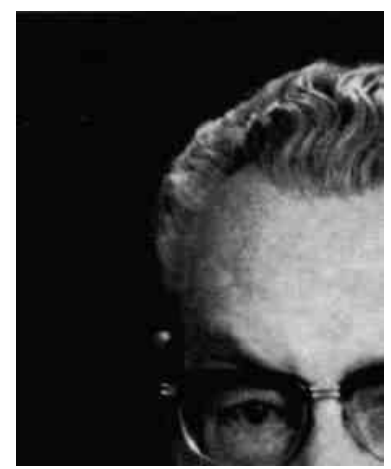

Professor Dr. Ferdinand May 